conditions which the Advisory Council stresses-a greatly increased number of scientīsts and engineers and a large flow of capital willing to seek investment in productive industry.

Confidence in the industrial future of Britain is derived from the fact that at least some British firms are as scientifically minded and as progressive as their counterparts in other countries. There is no fundamental technical reason why more should not emulate their example; and the Advisory Council has indicated, albeit somewhat tentatively, ways in which Government action could encourage this. It may well be necessary for others to repeat in more forthright terms what the Advisory Council has put so leniently; but the report also illustrates the need for the continuing survey and representations of the Advisory Council on Scientific Policy over its whole field, if the objectives in even one aspect such as that covered by the present report are to be achieved.

There are undoubtedly real advantages in the Advisory Council presenting its considered views on particular topics in such special reports; but it is perhaps unfortunate, particularly at the present time, that the annual report should be used as the medium of publication to the exclusion of discussion of all other topics. No reason is apparent from either the present, or last year's, report why reports on scientific man-power and on the exploitation of science by industry should not have been issued independently by the Council, and its annual report left free for the discussion of general aspects of scientific policy as appropriate. There are various topics of wide importance at the present time and on which scientists would be glad to know what advice the Advisory Council has given the Government. Has the Advisory Council, for example, accepted without protest the Government's procrastination over the proposed Science Centre, or has it pointed out the detrimental effect that such postponement is likely to have on the dissemination of scientific information and thus on the utilization of science by industry? What action has the Advisory Council taken to expedite Government action in the upgrading of selected technical colleges for higher technological education, or to secure the effective co-ordination of higher technological education under the University Grants Committee, as was indicated in an earlier report of the Advisory Council ? The failure of the Minister of Education to formulate a policy does not warrant the Advisory Council in leaving this matter with the hope that the Government's announcement regarding the Imperial College of Science and Technology "will soon be followed by effective action". And is there nothing further to report on the supply of science teachers, which so disturbed the Advisory Council a year ago ? Earlier reports have referred also to the utilization of the services of scientists and technologists in the Colonial territories and in the nationalized industries. Has the Advisory Council on Scientific Policy nothing further to say on these subjects? Is it satisfied that full use is being made of the services of scientists and technologists in these fields and that their advice is heeded?
There are, in fact, misgivings among scientists as to the use made of scientific advisers in the Colonial Service. The Secretary of State for the Colonies has so far done nothing to prevent the development of an atmosphere in which responsible men of science are unlikely to accept appointments and from which the Commonwealth will quickly suffer. So, too, on the nationalized industries, so responsible a periodical as The Engineer, in commenting recently on the annual report of the British Transport Commission, expressed fears that the changes initiated by the Government might seriously endanger technical efficiency, and expressed regret that political considerations had been allowed to introduce changes in organization of doubtful value which were bound to disturb profoundly the work of the Commission and its executives.

There is, in fact, an accumulation of evidence which suggests that little more than lip service is being paid by the Government to the claims of science to be heard in the counsels of the State and that objective advice is being disregarded. At such a juncture the silence of the Advisory Council on these matters is the more disquieting. It should be a prime function of the Council not merely to present advice to the Government, but also to satisfy the world of science that such advice is presented objectively and effectively, and that it receives due and reasonable consideration. It is to be hoped that means will be found whereby the Advisory Council on Scientific Policy will be able, not only to issue reports from time to time on matters of major topical importance, but also to provide the scientific world with an annual account of its activities in the many lesser fields in which scientific progress impinges on everyday affairs.

\section{THE AGRICULTURAL RESEARCH SERVICE}

$T$ HE Agricultural Research Council, which is appointed by the Committee of the Privy Council for Agricultural Research and Nature Conservancy, is responsible for the general supervision of Statefinanced agricultural research in Great Britain. Established in 1931, it has marked its coming of age by issuing a 54-page booklet, which is both a directory to the Service and an account of the functions of the Council*.

The recent growth of State expenditure in Britain on agricultural research is remarkable, and reflects the growing recognition of the vital importance of agriculture in the national economy. In 1930 State expenditure on research was about $£ 250,000$, in 1940 it was $£ 800,000$, in $1950 £ 2,600,000$, and in 1952 $£ 3,200,000$. The first figure represents about $0 \cdot 1$ per cent, and the last figure about 0.3 per cent of the gross value of agricultural output in the corresponding year. The figure $0 \cdot 3$ per cent may be considered too low for such an essential industry as agriculture to spend on scientific research ; but it should be remem* The Agricultural Research Service. Pp. 54. (London: H.M.S.O.
1953.) 28. 6 d. net. 
bered that it is not the industry but the taxpayer that provides the money, and that until the War the taxpayer had no reason to regard increased agricultural production at home as a matter of urgency. The agricultural research service should be satisfied that a four-fold increase in its cost since 1940 indicates that the public now recognizes its importance.

The agricultural research service has no formal constitution, and the term is used to comprise the activities of the agricultural research institutes and units, numbering between thirty and forty, which are financed by the State and supervised by the Agricultural Research Council. The service grew haphazardly. It may be said to have started in 1843 with the foundation of the Rothamsted Experimental Station-the oldest agricultural research institute in the world-by Sir John Lawes as a private venture. Other research institutes, dealing especially with various branches of horticulture, were afterwards founded by private benefactions or by funds provided by growers' associations. University departments also began research in different branches of plant and animal production. One significant result of this haphazard growth has been that there is no agricultural research station in Great Britain; but a number of independent institutes each concerned with some specialized branch of agriculture such as dairying, grassland, animal or plant breeding, etc.

Public money was not provided for agricultural research until 1910, and was at first administered by the Development Commission, which was responsible for allocating the money to the various institutes and university departments and thus exercised some co-ordination over the development of agricultural research as a whole. It proposed the setting-up of several new institutes some of which came into being after the First World War, which had at least established the right of British agriculture to survive. The Government's proportion of the cost of research increased rapidly, and as the need for closer coordination in the administration of the public funds grew the Agricultural Research Council was set up, first, to act as scientific advisers to the Development Commission, and afterwards to take over the responsibilities for agricultural research formerly discharged by the Commission. Agricultural research, like medical research and industrial research before it, was thus formally recognized as a govermment responsibility.

One of the first acts of the Agricultural Research Council was to survey the work of the research institutes with reference to current national needs, and it was decided that research on animal diseases should be expanded. The Council therefore set up the first of its own research stations at Compton, Berks, to study contagious abortion and other diseases of livestock, and afterwards three other stations. Ten smaller research 'units', concerned with special aspects of agricultural science, are also directly administered by the Council and operate in university departments where their work can be most effectively carried out. Through these units the Council can support fundamental research for which the environment and facilities of a university are often more suitable than those of a Statesupported research station. In all, the Council has a staff of nearly a hundred qualified scientific workers in its stations and units.

The Council's aim is "to review, co-ordinate and facilitate all agricultural research in progress, to promote new research where necessary, and to ensure so far as possible that the scientific man-power and other resources available are used to the best purpose". Its prime duty is thus co-ordination, the necessity of which is obvious when the wide field of agricultural research, embracing almost every branch of natural science, and the independent status of most of the research institutes are borne in mind. Besides operating the fourteen stations and units directly under its control, the Council gives advice (which, since the Council holds the purse strings, may occasionally amount almost to commands) on research programmes, staff and budgets to twenty-one institutes in Great Britain that derive most of their funds from the Ministry of Agriculture or the Department of Agriculture for Scotland. No central direction of research, however, is attempted, it being a cardinal principle of the Council that research workers should be free to develop their individual interests within the general requirements of the service. Members of the Council are selected mainly on account of their eminence in science and their ability to appreciate the conditions in which scientific research can best be carried out. There appears to be adequate appreciation of the necessity to promote fundamental research, of which a certain amount is done with public money at research institutes; but in genera] the Council considers that fundamental research is the province of the university departments over which the Council has no control, although it maintains close contact with them and, indeed, makes numerous grants to them to assist lines of research which may assist the solution of some agricultural problem.

Three standing committees-dealing with animal research, plant and soil research, and agricultural engineering--together with the Soil Survey Research Board assist the Council in formulating a research policy, and these in turn can call upon the advice of twenty-five technical committees or conferences the purpose of which is to keep in touch with problems and progress in specific subjects such as animal climatology, foot-and-mouth disease, dairy machinery, bracken control, drainage, red-spider mite and strawberry diseases. In this way a general policy can be drawn up without losing touch with the requirements of the individual research workers on whose ability and skill the Council recognizes the success of the research service must ultimately depend.

Research policy, particularly in agriculture where results appear slowly, must be long-term; nevortheless it has to be related to the shorter-term agricultural policy of the Government. When the Agricultural Research Council was established in 1931 the trend in government policy was towards the encouragement of livestock farming, and, as already stated, the Council paid special attention to research into animal diseases. Its aim is still to keep in step with post-war 
agricultural policy with its emphasis on an all-round increase in agricultural production. The Council maintains effective liaison with the Ministry of Agriculture and the Department of Agriculture for Scotland through the two Agricultural Improvement Councils that were set up during the War for that purpose and to advise the government departments on the best means of incorporating research results into practice, and the Agricultural Research Council on the problems requiring investigation. The Agricultural Improvement Councils are closely linked with the advisory services which, in their turn, are in direct contact with the farming community. Thus effective channels exist whereby not only can prompt application of the results of research to farming practice be achieved, but equally the demands of the agricultural industry can be brought to the notice of scientists at the highest level. The administration of such a complex service, from the many first-rate scientific intellects now working for agriculture to the vast multitude of farmers who may make use of the sifted and intermingled results of specialized research, is necessarily complex, but it works remarkably well. Much of the credit for that is due to the spirit of partnership with which the Agricultural Research Council has imbued the whole of the research service.

\section{AUTOMATIC CONTROL OF MECHANISMS AND INDUSTRIAL PROCESSES}

Servomechanisms and Regulating System Design By Harold Chestnut and Robert W. Mayer. (General Electric Series.) Vol. 1. Pp. xiii + 505. (New York : John Wiley and Sons, Inc.; London : Chapman and Hall, Ltd., 1951.) 62s. net.

Fundamentals of Automatic Control

By G. H. Farrington. Pp. xiit 285. (London : Chapman and Hall, Ltd., 1951.) 30s. net.

An Introduction to the Theory of Control in Mechanical Engineering

By R. H. Macmillan. Pp. xiv+195. (Cambridge: At the University Press, 1951.) 30s. net.

NE of the most interesting features of the development, during the past decade, of scientific thought in the field of applied science has been the building up of a philosophy of 'systems having a closed sequence of dependence'. Such systems, in the engineering field, may range in type and application from an automatic pilot for the navigation of an aircraft to the control of a complete chemical manufacturing process. Some of the theoretical concepts which have evolved from the coalescence of several independently developed branches of theory concerning control and communication have proved to be of a very general significance, not only in relation to engineering but even in such apparently unrelated fields as economics and biology.

The three books under review, although directly concerned with the engineering applications of control theory, serve to illustrate both the wide scope of the subject and the variety of ways in which it may be approached. All three start from simple fundamental considerations. H. Chestnut and R. W. Mayer, in their book on "Servomechanisms and Regulating System Design", after developing in a straightforward fashion the basic differential equations of electrical and mechanical systems, deal in considerable detail with the method of solution based on the Laplace transform and apply the method to very simple control problems. The central problem of control system behaviour, that of stability, is given very thorough consideration; in particular, steady-state analysis in terms of the Nyquist criterion. This is followed by a fairly detailed review of control system elements, mechanical, hydraulic and electrical, and their transfer functions, and of types of feedback control systems. Then the application of the complex plane plot in system analysis and in system design is treated.

Following this, attention is directed to the advantages for purposes of synthesis, rather than analysis, offered by design methods based on the work of H. W. Bode on the relationship between attenuation and phase in electrical networks, and the 'attenuation and phase diagram' method is developed and employed on representative problems including multipleloop and multiple-input systems. The book concludes with a chapter describing the use of charts relating the steady state and transient response to the openloop attenuation characteristics necessary to obtain the response.

This book constitutes an introduction to a practical method of control system design, and the development of the subject is clear and well suited to its direct purpose. It must, however, be recognized that there is a gap between the development from fundamental principles and the design method based on 'Bode's theorems which is bridged in only a rather slender fashion. There is an excellent bibliography, and a series of examples for solution is given at the end of the book.

"Fundamentals of Automatic Control", by G. H. Farrington, is essentially a presentation of the principles of automatic control applied to industrial processes. Although the principles underlying the automatic control of a process or of a complete plant may be basically the same as those governing, say, the control of position of the output member of some form of electromechanical system, it is immediately evident, on comparing two text-books dealing with these separate branches, that the approach and much of the nomenclature differ widely. This book formulates in a very satisfactory way the mathematical equations representing typical generalized control systems, and develops performance criteria. The theory is built up on considerations relating to the control of such quantities as temperature, pressure, fluid flow or humidity. Of particular interest is the utilization in the solution of process control problems of electrical analogues for the actual physical phenomena involved and the establishment of the equivalent electrical networks. The electrical analogue is also turned to good account in a chapter dealing with systems having distributed constants, the formulæ of the electrical transmission line being used as a basis for the analysis. There are chapters dealing with the principles of plant analysis and with the analysis of controlling units of pneumatic type, and there is a brief final section on control selection and adjustment. Taken as a whole, the treatment is rather condensed, and there are a good many instances of topics being introduced but developed in 